\title{
RHINOLOGY
}

\section{Correction of alar rim retraction by lateral crural extension graft}

\author{
Correzione della retrazione alare mediante il lateral crural extension graft \\ Tito Matteo Marianetti ${ }^{1}$, Antonio Moretti ${ }^{2}$ \\ ${ }^{1}$ Assunzione di Maria Santissima Clinic, Rome, Italy; ${ }^{2}$ Department of Medical, Oral and Biotechnological Sciences, \\ Otorhinolaryngology Clinic, Clinical Hospital SS. Annunziata, "G. d'Annunzio" University, Chieti, Italy
}

\begin{abstract}
SUMMARY
Alar rim retraction is a deformity of the alar conformation that can primarily occur in patients who have not undergone surgery or it can represent the outcome of a previous rhinoplasty surgery. Several surgical techniques for the treatment of alar retraction have been described. This study describes the lateral crural extension graft, a versatile and simple graft to correct alar retraction. Between 2015 and 2017, 47 patients who presented alar rim retraction underwent open septorhinoplasty surgery using the lateral crural extension graft. The retraction was assessed by using the classification systems by Kim for frontal view and Gunter for profile view. Postoperative photos with a minimum follow-up of 12 months were compared with preoperative photos by measuring in millimeters the improvement of alar rim retraction. The mean distance between the alar rim and the long axis of the nostril was reduced by $2.7 \mathrm{~mm}$ on average (range, 2.1 to $3.8 \mathrm{~mm}$ ), showing an objective effectiveness of the procedure. In 7 cases, the correction was incomplete due to excessive cutaneous scarring retraction which caused partial recurrence of alar rim retraction. On the basis of a VAS rating scale, $32(68 \%)$ of 47 patients said they were very satisfied with the outcome, 9 $(19 \%)$ were satisfied and $6(12 \%)$ were not very satisfied. The lateral crural extension graft is a simple and reliable method for correcting alar rim retraction. In cases of severe skin deficiency, it is not sufficient and a composite graft reconstruction must be used.
\end{abstract}

KEY WORDS: alar retraction, lateral crus retracted, extension graft, alar rim retraction

\section{RIASSUNTO}

La retrazione dell'ala nasale è un'alterazione della conformazione alare che può ritrovarsi sia in rinoplastiche primarie che in rinoplastiche di revisione. Sono state descritte diverse tecniche chirurgiche per la soluzione del problema. In questo studio descriviamo il "lateral crural extension graft", un innesto versatile e semplice da utilizzare. Tra il 2015 e il 2017 , 47 pazienti presentanti retrazione dell'ala nasale sono stati sottoposti ad intervento chirurgico di settorinoplastica open con utilizzo del "lateral crural extension graft". La retrazione è stata determinata in base alle classificazioni di Kim per la visione frontale e di Gunter per la visione di profilo. Le foto post-operatorie con un follow-up minimo di 12 mesi sono state paragonate con quelle preoperatorie misurando in millimetri il miglioramento della retrazione alare. La distanza media tra l'alar rim e l'asse maggiore della narice è stata in media ridotta di 2,7 $\mathrm{mm}$ (range, 2,1 to 3,8 $\mathrm{mm}$ ), indicando un'oggettiva efficacia della procedura. In 7 casi la correzione è stata incompleta per presenza di retrazione cicatriziale cutanea che ha causato una parziale recidiva della retrazione alare. Sulla base di una scala di valutazione VAS, 32 dei 47 pazienti (68\%) erano molto soddisfatti del loro risultato, 9 (19\%) erano soddisfatti e 6 (12\%) poco soddisfatti. Il "lateral crural extension graft" è un metodo semplice ed affidabile per la correzione della retrazione dell'ala nasale. Nei casi in cui sia presente un deficit cutaneo importante, esso non è sufficiente e bisogna far ricorso al "composite graft".

PAROLE CHIAVE: retrazione alare, retrazione crus laterale, retrazione rima alare
Received: July 5, 2019

Accepted: October 27, 2019

\section{Correspondence}

Tito Matteo Marianetti

viale delle Provincie 55/18, 00162 Rome, Italy

E-mail: titomatteo.marianetti@tin.it

Funding

None.

\section{Conflict of interest}

The Authors declare no conflict of interest.

How to cite this article: Marianetti TM, Moretti A. Correction of alar rim retraction by lateral crural extension graft. Acta Otorhinolaryngol Ital 2020;40:211-216. https://doi. org/10.14639/0392-100X-N0382

(c) Società Italiana di Otorinolaringoiatria e Chirurgia Cervico-Facciale

\section{(c) (i) $(\$$}

This is an open access article distributed in accordance with the CC-BY-NC-ND (Creative Commons Attribution-NonCommercial-NoDerivatives 4.0 International) license. The article can be used by giving appropriate credit and mentioning the license, but only for non-commercial purposes and only in the original version. For further information: https:// creativecommons.org/licenses/by-nc-nd/4.0/deed.en 


\section{Introduction}

Alar retraction (AR) is a common clinical-surgical problem that is very difficult to resolve. It can be either primary or resulting from aggressive cephalic trim of the lower lateral cartilage during a previous rhinoplasty surgery.

In its primary forms, the alar rim is related to congenital cartilaginous and/or cutaneous deficiency or to the particular conformation and positioning of the lateral crura. More often, it is the outcome of previous rhinoplasty surgery with excessive removal of the alar cartilage and/or vestibular skin. The outcome of an aggressive surgery on the alar cartilage and adjoining skin, together with excessive resection, usually brings about weakening of the cartilage that ends up retracting upwards, causing exposure and alteration of the alar-columellar unit ${ }^{1}$.

In addition to provoking severe aesthetic problems, alar retraction associated with overresection or malpositioning of the lateral crura may also be responsible for functional problems related to the collapse of the external nasal valve. Several classifications of alar rim retraction have been proposed, hence the altered relationship between the alar rim and the long axis of the nostril. The most wellknown and universally accepted classifications are Gunter's for the lateral view ${ }^{2}$, which defines discrepancies in the alar-columellar relationship, and Kim's for the frontal view ${ }^{3}$. In these classifications, the authors distinguish alar retraction in medial, central and lateral, depending on whether the retraction affects the most medial portion of the alar rim (alar notching), the midpoint or the alar base. The techniques which involve correction of alar retraction are even more numerous.

Alar contour graft or alar rim graft is a commonly used graft which allows correction of mild cases of alar retraction. When this deformity is caused by the weakness of the soft triangle, due to malpositioning of the lateral crura, it is appropriate to correct this conformation of the alar rim through caudal repositioning of the lateral crura associated or not to the lateral crural strut graft which depends on the integrity of the cartilage. The alar spreader graft and the upper lateral-alar interposition graft may be useful, but can often have the secondary effect of creating a bulk on the tip of the nose in the central or lateral portion respectively. In the most serious cases of alar retraction, the most appropriate solution is represented by a composite graft harvested from the cymba concha ${ }^{4}$.

In this study, we describe, propose and analyze the function, method and aesthetic impact of the lateral crural extention graft (LCEG), which enables the caudal extension of the lateral crura of the alar cartilage to improve the morphology and stability of the alar rim.

\section{Materials and methods}

We have analysed pre-, post- and intraoperative photos of all patients who underwent a primary or revision septorhinoplasty surgery in the three-year period from 2015-2017. A total of 310 patients were treated. The mean follow-up period was 17 months (range, 12-23 months). Forty-seven patients whose preoperative photos presented an alar retraction greater than $2 \mathrm{~mm}$ in frontal or lateral projection were selected and the retraction was determined based on the classifications of $\mathrm{Kim}^{3}$ for frontal view and Gunter ${ }^{2}$ for profile view.

All patients underwent septorhinoplasty with the open technique and in all cases an alar extention graft was bilaterally grafted (Fig. 1).

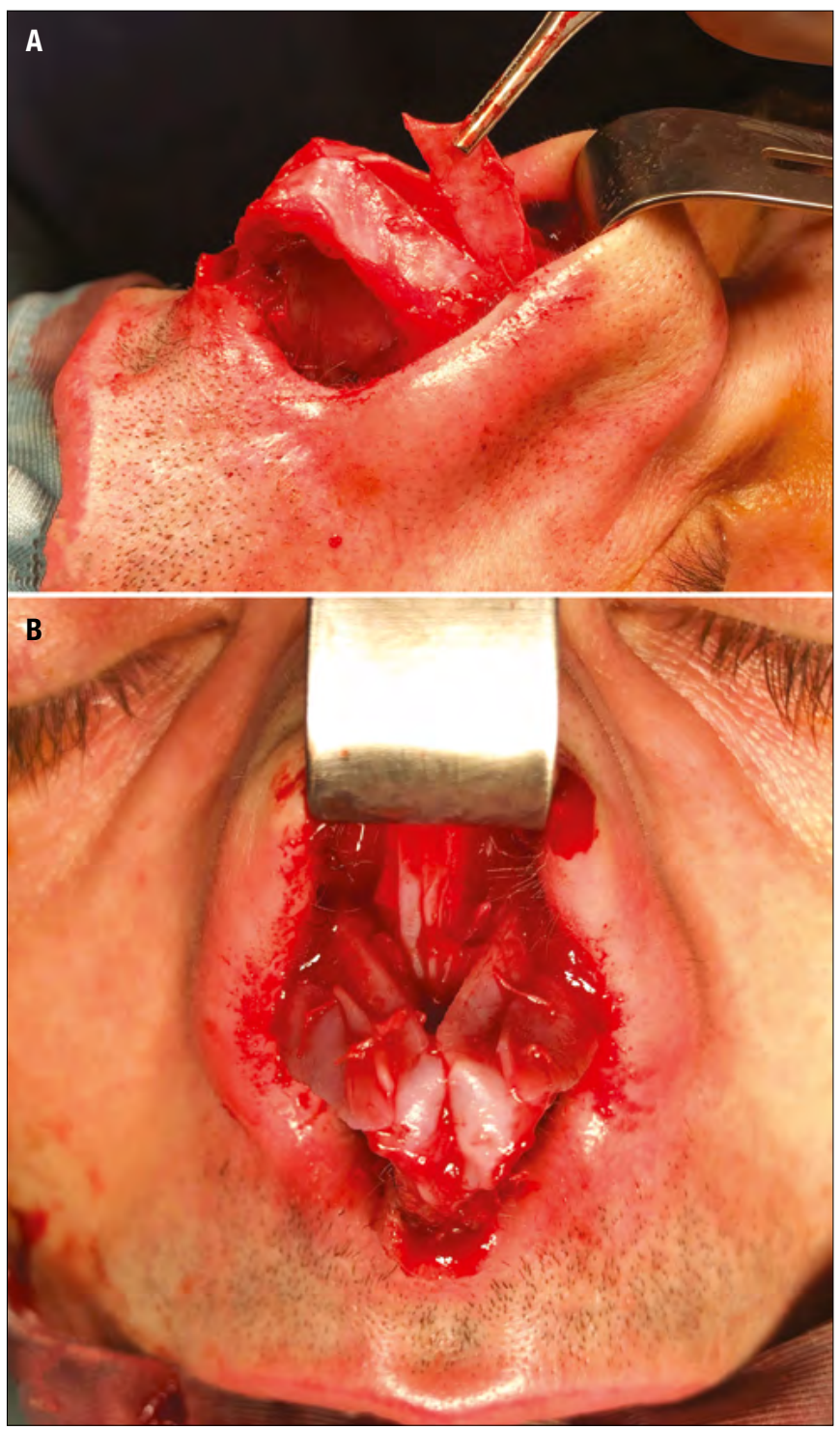

Figure 1. A) Intraoperative image showing the harvesting of the cephalic portion of the lateral crus used as grafting material for lateral crus extension graft. B) Intraoperative view of the bilateral lateral crural extension graft. 
Photographs were taken in classic poses with a Canon EOS $60 \mathrm{D}$ digital single-lens reflex camera with a $105-\mathrm{mm}$ macro lens. Postoperative photos with a minimum follow-up period of 12 months were compared with preoperative photos by measuring improvement of alar retraction in millimeters. Pre- and postoperative photographs were compared digitally by overlapping tragus and the external cantus in order to have a reliable comparison in measurements. Data on surgical technique, which were applied to individual cases and adapted with respect to the entity of the deformity to be corrected, were extracted from the worksheet on the surgical maneuvers performed and attached to medical records and intraoperative photos. Through a patient survey, based on a VAS scale (with scores from 0 to 100), patient satisfaction was evaluated and was categorised into three groups: very satisfied (VAS score range 90-100), satisfied (VAS score 5089 ) and unsatisfied (VAS score less than 50).

\section{Surgical technique}

By using an open approach, an incision closer to the alar rim is made rather than making it along the caudal border of the alar cartilage. After exposing the cartilages of the tip, a sufficient amount of vestibular skin is dissected in the caudal portion, creating a large pocket inside the alar cutaneous margin. During this phase, particular care must be taken in the dissection of the area with maximal retraction since it must be well detached to allow subsequent extension by the graft.

In fact, before dissection the skin in this region, especially in revision rhinoplasty, is firm and tightly adherent and does not enable positioning of the extension graft. Next, depending on the lateral crura, the graft is made and can be harvested from the cephalic border of the alar cartilage, especially in primary cases or from the cymba concha in revision rhinoplasty. In particular, the cavum conchae, having a slight natural concavity, lends itself as an ideal donor site for reconstructing the ala.

The graft, which should be at least $6 \mathrm{~mm}$ wide, is then placed at the level of the caudal margin of the lateral crus with a $2 \mathrm{~mm}$ overlap to allow stabilisation of the same through mattress sutures in PDS 6.0. The overlapping and mattress sutures ensure greater graft stability together with a greater ability to stretch the retracted ala compared to edge-to-edge sutures. Finally, the graft is inserted into the mucocutaneous pocket created in the alar margin and the vestibular skin is sutured with rapid 5-0 Vicryl, which should not be too tight.

\section{Results}

Thirty-three patients were women and 14 men with a mean age of 32 years (range, 21-49 years), all Caucasians, were assessed. In 13 cases, there was congenital alar retraction, while the remaining 34 patients had undergone previous rhinoplasty surgery. According to Kim's frontal classification system, 28 of 47 patients affected by alar retraction fell into Type 2 (central retraction), 13 into Type 3 (lateral retraction) and 6 into Type 1 (medial retraction). Taking into account Gunter's classification system for profile view, the distance between the alar rim and the long axis of the nostril, which was measured by the lateral projection photos, ranged from 2.8 to $5.9 \mathrm{~mm}$, with an average value of $3.4 \mathrm{~mm}$.

All patients underwent septorhinoplasty with the open technique and in all cases an alar extention graft was bilaterally grafted. Thanks to the use of the LCEG the distance between the alar rim and the long axis of the nostril was reduced on average by $2.7 \mathrm{~mm}$ (range, 2.1 to $3.8 \mathrm{~mm}$ ), indicating an objective efficacy of the procedure (Figs. 2-5). No complications were observed except for one complaint of a small palpable cartilaginous step-off on the alar margin. In 7 cases,

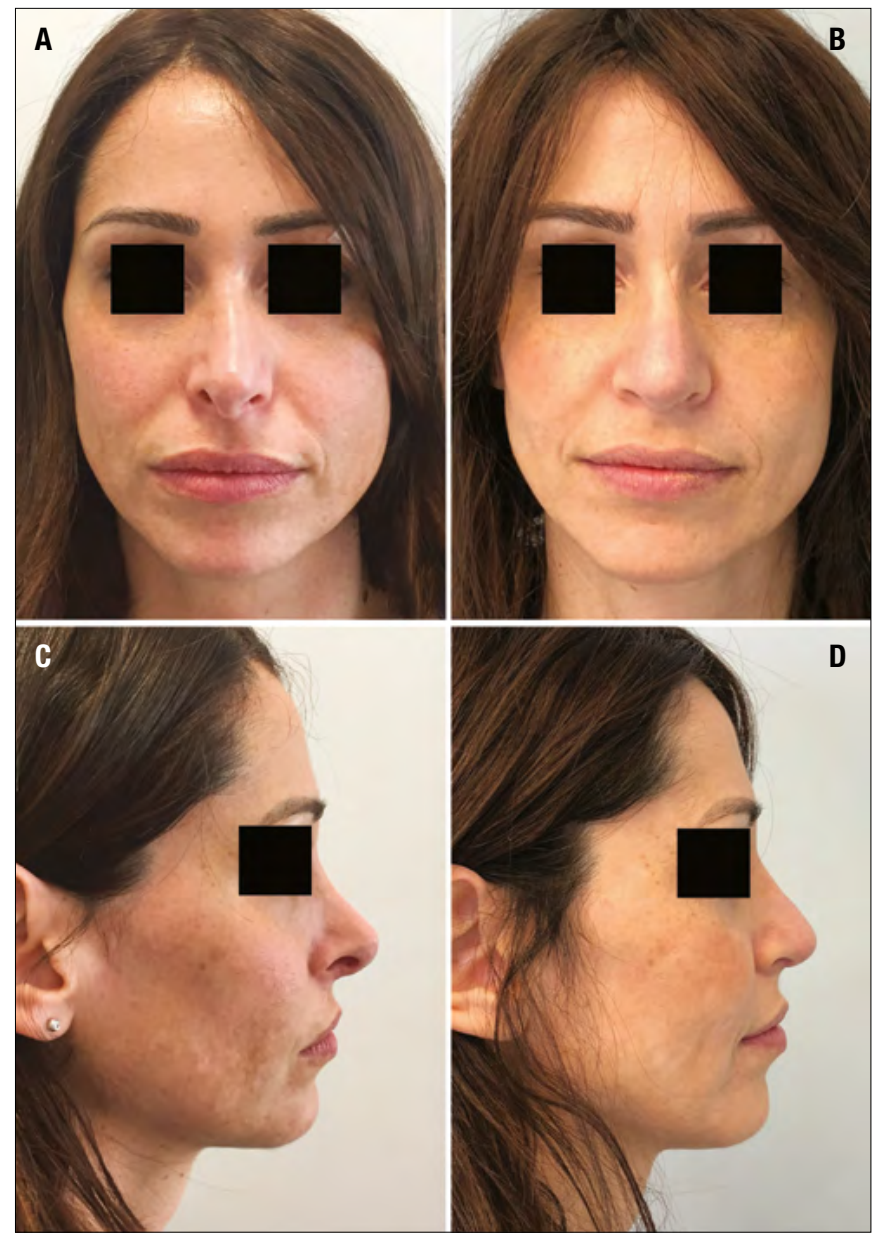

Figure 2. CASE 1:Patient affected by secondary alar retraction corrected by bilateral lateral crura extension graft. A) Preoperative frontal view. B) Post-operative frontal view. C) Preoperative right profile. D) Post-operative right profile. 

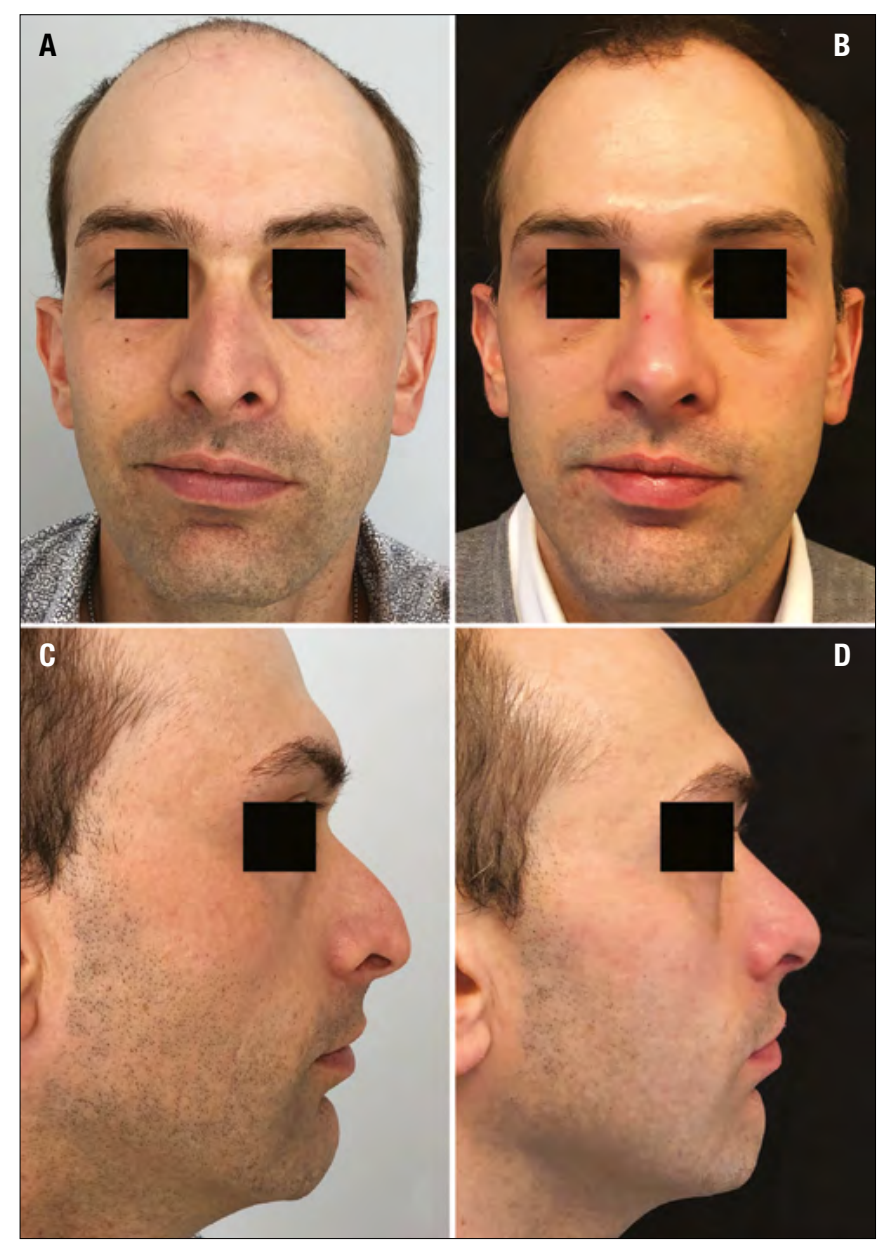

Figure 3. CASE 2: Patient affected by primary alar retraction corrected by bilateral lateral crural extension graft. A) Preoperative frontal view. B) Post-operative frontal view. C) Preoperative right profile. D) Post-operative right profile.

the correction was incomplete due to the presence of cutaneous scars which caused a partial recurrence of the alar retraction. On the basis of a VAS rating scale, 32 (68\%) of 47 patients said they were very satisfied with the outcome, 9 (19\%) were satisfied and 6 (12\%) were not very satisfied.

\section{Discussion}

For the rhinoplasty surgeon, the alar retraction, both unilateral and bilateral, represents a challenge that is difficult to manage, especially when it is the outcome of excessive and aggressive surgical surgery at the level of the lower lateral cartilage structures and adjacent soft tissues. Treatment is simpler in primary cases or when there is no evidence of a very strong deformity. In the diagnostic phase, it is appropriate to have an evaluation in the lateral view following Gunter ${ }^{2}$, but this information should also be coupled with evaluation in the frontal view ${ }^{3}$.
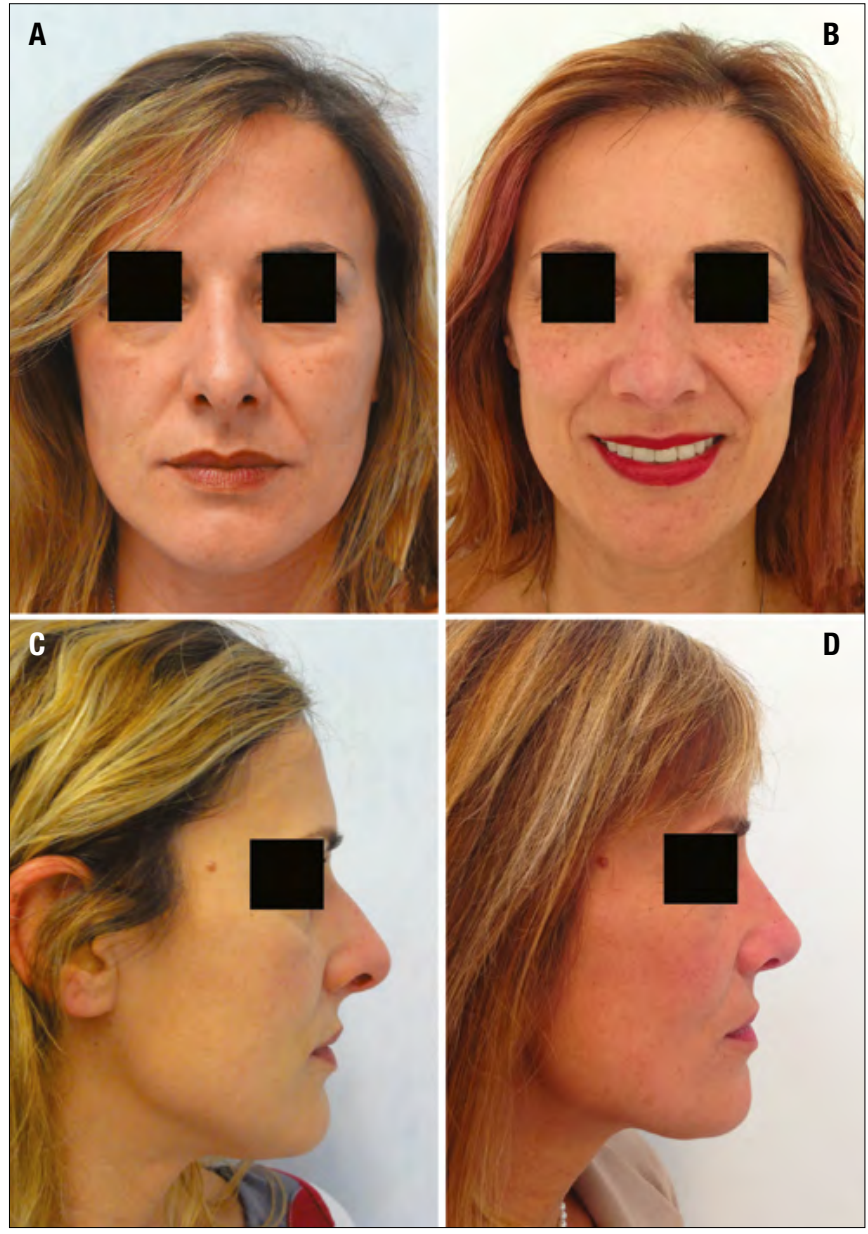

Figure 4. CASE 3: Patient affected by primary alar retraction corrected by bilateral lateral crural extension graft. A) Preoperative frontal view. B) Post-operative frontal view. C) Preoperative right profile. D) Post-operative right profile.

In our experience, we observed that in iatrogenic cases the deformity is basically correlated to a pre-existing alar retraction at the first surgery that remained unnoticed because it was minor. This is especially true if associated with malpositioning of the lateral crura that wasn't corrected by surgery, and which is usually the stigma of overly aggressive treatments with abundant resection and interruption of the alar cartilage. Other elements that can contribute to alar retraction are the integrity of cartilage and the manipulation of alar soft tissues, especially when the skin is thin.

As part of possible correction treatments for alar retraction, it is possible to state that the surgical strategy to be adopted is closely linked to the entity of the deficiency to be corrected. For example, mild and medium-sized alterations can be resolved with an alar rim graft. This is a graft that can be easily inserted at the level of the alar contour, with both closed and open approaches. The technique includes positioning of a strip of cartilage, which is usually a septal one, 

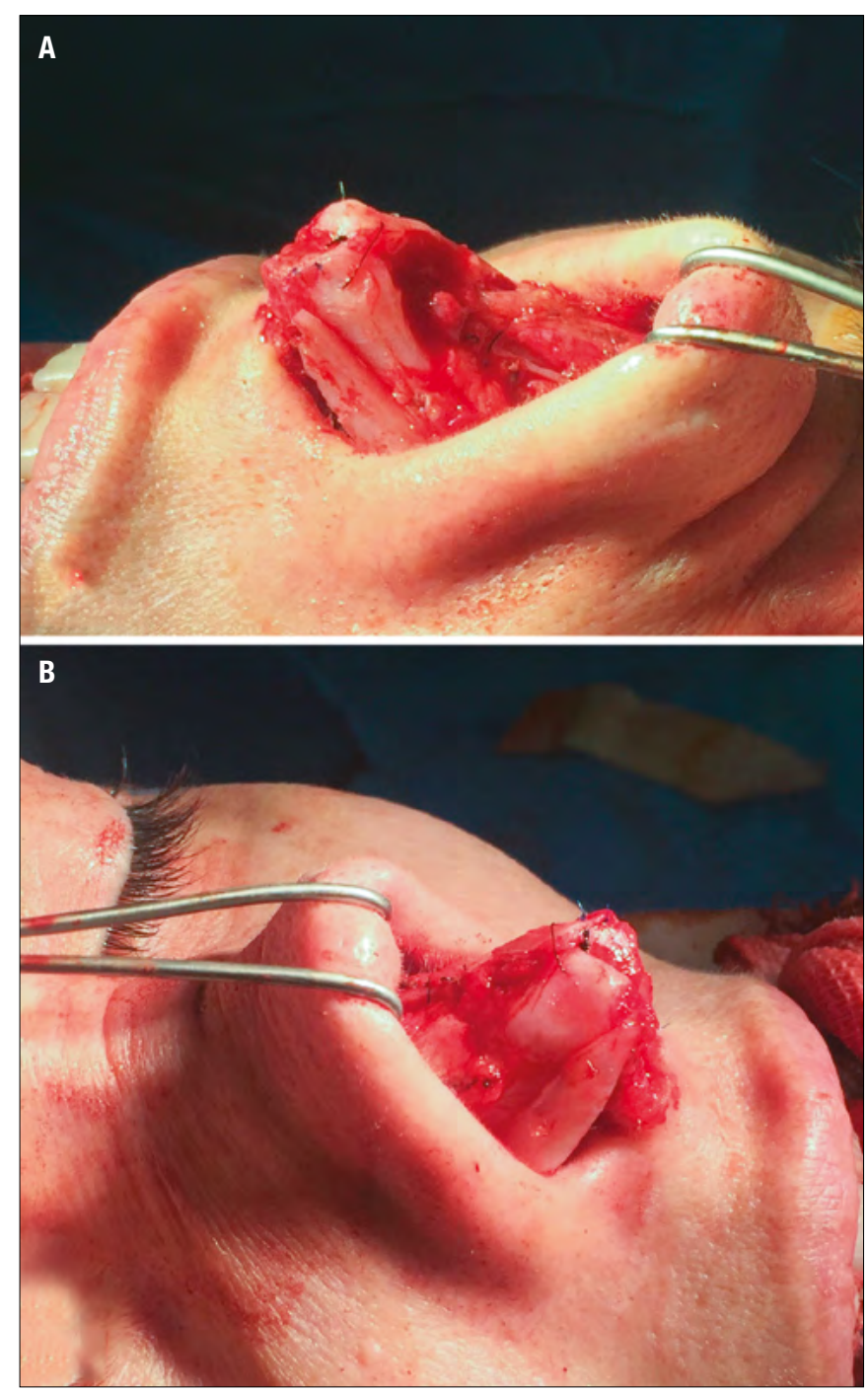

Figure 5. Intraoperative view of the patient showed in Fig. 2. A) Left lateral crus extension graft. B) Right lateral crus extension graft.

into a pocket harvested from the alar rim where there is no cartilage tissue. The success of this procedure depends on soft tissues and degree of extension of the alar rim ${ }^{5}$.

In cases where the defect appears to be more complex and considerably evident, retraction and pinching are related to excessive rotation of the tip, which results from inaccurate resection and excessive medialisation of the alar cartilage.

This condition can be effectively solved using an alar spreader graft, but the graft must include complete detachment with release of tissues at the level of the scroll area in order to be able to slide down the positioning of the lateral crura. This graft, which is placed and fixed between the septum-upper lateral cartilage junction in the most caudal portion and the cephalic border of the alar rim, must always provide for wide detachment of the tip's support structures, especially between the lateral cartilages, so as to obtain a more caudal positioning of the alar rim.

Sutures must be well positioned to prevent extension of the nose and a hanging columella due to excessive sliding downwards resulting from detachment and tissue release. This is useful when correcting moderate and severe alar retraction with a rotated and pinched tip, but a visible bulbous evidence on the supratip area may remain.

The lateral crural strut graft proposed by Gunter in $1997^{6}$ represents a possible resolution to alar retraction associated with malpositioning because it allows to place the entire base of the nostril and the alar rim in a more caudal position. The lateral crural strut graft is inserted below the alar margin and the lateral crus, which is totally detached up to the level of the piriform aperture. In case of isolated and localised alar retraction, this procedure is not recommended due to prolonged oedema and possible and unpredictable reconstructive outcomes on the alar rim.

As an alternative to the lateral crural strut graft, it is possible to use an intercartilaginous graft between the lower margin of the upper lateral cartilage and the upper margin of the lateral crura of the alar cartilage ${ }^{7}$. This procedure involves repositioning of the lateral crus downwards by inserting a spacer coupling after extensive detachment. The intercartilaginous graft can be more easily inserted into iatrogenic ARs since the upper and lower lateral cartilages usually show separation as a result of the modeling procedures that allows placement and stabilisation of the graft. In primary alar retractions, on the contrary, the accommodation for the graft must be created by separating the two cartilages. The intercartilaginous graft enables the correction of significant alar retraction of medium-severe degree, but it is not possible to place it in cases of absence or excessive resection of the alar cartilage or when there is a simultaneous retraction of soft tissues with insufficient skin. In these cases, it is essential to use a composite chondrocutaneous graft ${ }^{8}$. This is usually harvested from the auricular basin and allows correction of complex alar retraction in which loss of substance due to excessive scar retraction has occurred. The grafted cartilaginous component, which is usually smaller than the cutaneous one, must provide complete coverage even by the recipient tissues to avoid excessive phenomena of reabsorption. Another critical point in the use of this graft involves the symmetry of the nasal orifices, especially when there is bilateral reconstruction. This drawback is closely linked to the unpredictability of post-surgical healing and tissue repair processes.

According to our experience, the LCEG offers a valid alternative for cases in which it is necessary to provide the cartilage support necessary for the retracted ala. It is a simple and enduring technique, and can often replace the caudal 
repositioning procedure of the lateral crura in case of their malpositioning ${ }^{9}$. In fact, in these cases the same cartilage which has been removed from the cephalic portion of the crura can be placed caudally to obtain a different orientation of the lateral crura at the end of the procedure. However, the LCEG offers greater guarantees of symmetry and is easier to achieve at a technical level compared to repositioning of the crura. Moreover, it is a graft that allows obtaining a more solid and predictable cartilage support than the alar rim graft.

The cartilage necessary for the graft to stretch the lateral crura can also be obtained from the auricular concha ${ }^{4,10}$, especially in secondary cases where it is not possible to harvest it from the nose due to the small amount of cartilage available or in order not to weaken the pyramid structure. However, in cases where alar retraction is provoked by a cutaneous deficiency as well as a cartilaginous one, a composite graft is the only treatment option.

\section{Conclusions}

Alar retraction can be corrected with different surgical methods. The more caudal alar portion has thicker skin and is not supported by cartilage. To obtain caudal extension of the vestibular skin of the margin and the alar skin, it is also necessary to take into account the relationship between the tip and the width of the alar base; frontal classification of alar retraction is very useful when choosing the surgical method.

The outcomes of this study objectively confirm that excessive surgical manipulation of the lateral crura can lead to alar retraction and that the LCEG has a measurable improvement effect on this retraction. This graft can also be used in primary cases of alar retraction or for prophylactic purposes to prevent it by using the cephalic trim of the lateral crura.
In most cases, correction of the retraction with an alar graft or an LCEG is very effective, although when the retraction is more lateral it should be coupled with reduction of the alar base. On the other hand, when the retraction is also related to a deficiency of the vestibular and alar soft tissues, it is appropriate to use a composite graft.

\section{References}

1 Alexander AJ, Shah AR, Constantinides MS. Alar retraction etiology, treatment, and prevention. JAMA Facial Plast Surg 2013;15:268-74. https://doi.org/10.1001/jamafacial.2013.151

2 Gunter JP, Rohrich RJ, Friedman RM. Classification and correction of alar-columellar discrepancies in rhinoplasty. Plast Reconstr Surg 1996;97:643-8. https://doi.org/10.1097/00006534-199603000-00026

3 Kim JH, Song JW, Park SW, et al. Correction of alar retraction based on frontal classification. Semin Plast Surg 2015;29:278-85. https:// doi.org/10.1055/s-0035-1566111

4 Jang YJ, Kim SM, Lew DH, et al. Simple correction of alar retraction by conchal cartilage extension grafts. Arch Plast Surg 2016;43:564-9. https://doi.org/10.5999/aps.2016.43.6.564

5 Rohrich RJ, Raniere JJr, Ha RY. The alar contour graft: correction and prevention of alar rim deformities in rhinoplasty. Plast Reconstr Surg 2002;109:2495-508. https://doi.org/10.1097/00006534-20020600000050

6 Gunter JP, Friedman RM. Lateral crural strut graft: technique and clinical applications in rhinoplasty. Plast Reconstr Surg 1997;99:94352. https://doi.org/10.1097/00006534-199704000-00001

7 Gruber RP, Kryger G, Chang D. The intercartilaginous graft for actual and potential alar retraction. Plast Reconstr Surg 2008;121:288e-96e. https://doi.org/10.1097/PRS.0b013e31816c3b9a

8 Chen C, Patel R, Chi J. Comprehensive algorithm for nasal ala reconstruction: utility of the auricular composite graft. Surg J 2018;4:5561. https://doi.org/10.1055/s-0038-1639581

9 Mohebbi A, Azizi A, Tabatabaiee S. Repositioned lateral crural flap technique for cephalic malposition in rhinoplasty. Plast Surg (Oakv) 2015;23:183-8. https://doi.org/10.4172/plastic-surgery.1000933

10 Constantian MB. Indications and use of composite grafts in 100 consecutive secondary and tertiary rhinoplasty patients: introduction of the axial orientation. Plast Reconstr Surg 2002;110:1116-33. https:// doi.org/10.1097/01.PRS.0000021870.72613.FC 